\title{
A Survey of the Relationship Between Noised Pollution, Honey and Vitamin E and Plasma Level of Blood Sexual Hormones in Noise-Exposed Rats
}

\author{
Malek Kenani ${ }^{1}$;Asghar Rajabzadeh ${ }^{2}$; Ghasem Saki ${ }^{3}$; Ali Khodadadi ${ }^{4}$; Alireza Sarkaki ${ }^{3}$; \\ Alborz Jafai ${ }^{6}$; Masoud Hemadi ${ }^{6,}$ \\ ${ }^{1}$ Department of pathology, Faculty of Medicine, AhvazJundishapur University of Medical Sciences, Ahvaz, IR Iran \\ ${ }^{2}$ Department of Anatomy, School of Medicine, Ahvaz Jundishapur University of Medical Sciences, Ahvaz, IR Iran \\ ${ }^{3}$ Physiology Research Center, School of Medicine, Ahvaz Jundishapur University of Medical sciences, Ahvaz, IR Iran \\ 4 . \\ 5 Department of Immunology, School of Medicine, Ahvaz Jundishapur University of Medical Sciences,

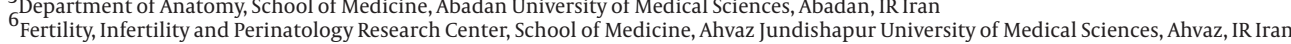 \\ ${ }^{*}$ Corresponding author: Masoud Hemadi, Fertility, Infertility and Perinatology Research Center, School of Medicine, Ahvaz Jundishapur University of Medical Sciences, Ahvaz, IR Iran. \\ Tel: + 98-6113201454; + 98-9127107299, Fax: + 98-6113335399, E-mail: mhemadi79@gmail.com
}

Received: March 25, 2014; Revised: November 12, 2014; Accepted: December 26, 2014

\begin{abstract}
Background: This study was conducted to examine the efficacy of honey and vitamin $\mathrm{E}$ on fertilization capacity of noise-exposed rats by assessing whether the plasma sexual hormones levels i.e. follicle stimulating hormone (FSH), luteinizing hormone (LH) and testosterone are altered in relation with noise stress.

Objectives: Therefore, this study aimed to evaluate the effects of honey and vitamin E on the levels of sex hormones and male fertilization capacity of noise-exposed rats.

Materials and Methods: This study targeted 24 male rats that were randomly divided into four equal groups including the control group that were not exposed to noise and experimental groups 1, 2 and 3 that were the untreated, honey treated and vitamin E treated groups, respectively; all of which were exposed to noise for 50 days. Next, in order to measure serum sexual hormones, blood samples of experimental and control groups were taken and analyzed. Also in order to investigate the fertility capacity of rats, the male rats of all groups were coupled with female rats.

Results: The results showed that in the male rats exposed to the noise stress, the levels of FSH and LH rose and the testosterone secretion fell sharply compared to not exposed rats. Additionally, the continuing effects of noise stress injury could reduce the weight of the fetus and the number of live fetuses and survival rate of the fetus. However, honey and vitamin E improved serum testosterone concentration, while declined plasma FSH and LH secretion in noise-exposed rats and enhanced fertility rate by increasing the rate of healthy alive fetuses.

Conclusions: It seems that noise pollution has harmful effects on the fertility of males. Also these findings may suggest the use of a natural curative approach rather than pharmaceutical drugs to optimize both neuroendocrine gonadal axis and testicular integrity induced by pathogenesis stress, and enhance fertility capacity in men.
\end{abstract}

Keywords: Antioxidants; Environmental; Stress; Noise; Sexual Hormones

\section{Background}

Stress is defined as a physiological response to bodies homeostasis disorders (1). Among environmental stresses, noise as a natural teratogenic agent is relatively more common and affects body systems including the reproductive organs to reduce the fertility rate and fetus health $(2,3)$. Some researchers have reported that some stresses, such as immobilization, heat and water restrictions alter serum sex hormone levels resulting a decrease in fertilization rate and implantation $(4,5)$. Also, some researchers showed that exposure to noise could change stress hormones such as corticosteroid, norepinephrine and adrenocorticosteroid while decreasing testosterone levels that cause a disruption in the testis integrity and consequently reduce the number of healthy spermatozoa $(6,7)$. Moreover, long-term exposure to noise can greatly increase sperm sensitivity to oxidative stress and in turn affect sperm capacity and acrosome reaction.

The testes, normally, have antioxidant agents that protect their germ cells from oxidative damage $(8,9)$. Nevertheless, in the mature spermatozoa when the production of free radicals increases, the physiological system will not respond. Finally, it has been suggested that using of antioxidants in everyday life is very important, as many biological problems are caused by free radicals which induce oxidative damage to lipids and proteins in the cell membrane (10). Natural antioxidants can prevent devastating changes in the spermatozoa. Honey and vitamin E are principle antioxidants that are abundantly found in nature. Honey as an anti-

Copyright (C) 2015, Ahvaz Jundishapur University of Medical Sciences. This is an open-access article distributed under the terms of the Creative Commons Attribution-NonCommercial 4.0 International License (http://creativecommons.org/licenses/by-nc/4.0/) which permits copy and redistribute the material just in noncommercial usages, provided the original work is properly cited. 
microbial and anti-inflammatory food is considered a biological antioxidant and has been shown to increase sperm number in rats without any effect on the serum FSH, LH and testosterone $(10,11)$.

The antioxidant identity of honey reflects its phenolic components (12) while other ingredients i.e. catalase, glucose, fructose, minerals including magnesium, potassium and calcium, and vitamin C and B increase its antioxidant properties $(11,13,14)$. Vitamin $\mathrm{E}$ is another antioxidant that is found in cell membranes and protects the cell membranes against hydrogen peroxides (15). Alpha-tocopherol is the natural form of vitamin E with high biological activity (16). Some reports have indicated that the key role of vitamin $\mathrm{E}$ in the testis is reducing oxidative stress $(17,18)$. Indeed, this vitamin has a protective effect on testicular function and increases male fertilization capacity (19). Overall, the effects of stress on reproductive activity are not well known. However, a series of neurological, paracrine and endocrine systems may be involved. To the best of our knowledge no study has evaluated honey and vitamin E effects on the levels of sex hormones, and the capacity of fertilization in noise-exposed rats, simultaneously. Therefore, this study aimed to evaluate honey and vitamin E effects on the levels of sex hormones and male fertilization capacity of noise-exposed rats.

\section{Objectives}

This study aimed to evaluate honey and vitamin E effects on the levels of sex hormones and male fertilization capacity of noise-exposed rats.

\section{Materials and Methods}

\subsection{Animals}

Twenty-four adult male Sprague Dawley rats weighing $200 \pm 20$ g were obtained from the Physiology Research Center (Ahvaz Jundishapur University of Medical Sciences; Ahvaz, Iran). The animals were acclimated to 22 $\pm 1^{\circ} \mathrm{C}$ and maintained under conditions of 12 hour-light and dark, with free access to tap water and commercial rat food. All procedures were approved by international guidelines and the Research Ethics and Animal Care and Use committee of Ahvaz Jundishapur University of Medical Sciences. Every effort was made to minimize the number of animals used and their suffering.

\subsection{Study Design}

The rats were randomly divided into four groups (six rats per group) and classified as follows: the control group that were not exposed to noise and experimental groups 1, 2 and 3 that were the untreated, honey treated (received 5\% honey dissolved in water) and vitamin E treated (received $75 \mathrm{mg} / \mathrm{mL}$ vitamin E dissolved in corn oil) groups, respectively. Experimental groups
2 to 4 were exposed to 90 to $130 \mathrm{~dB}$ of noise with a frequency of $300-350 \mathrm{~Hz}$ daily from 7 PM to $7 \mathrm{AM}$ for 50 days. The groups were transported to a room which had dimensions of $3 \times 4 \times 3$ meters and was lagged by wood and acoustic segments (anti-loud voice). In this room, white noise was produced at 19 o'clock for frequency of 300-350 Hz and intensity of 90-120 dB (20), and the set timer was arranged in a way that after 1 hour of operation and producing noise by the speaker, it would turn off for a few minutes (from 15 minutes to 60 minutes), before it operated again. It is important to mention that, this method prevented animals from gaining compatibility. The noise producing device changed the intensity and frequency of noise produced automatically in the district of minimum and maximum every two to three minutes and this also aided with the elimination of animal compatibility (21). For evaluating the amount and intensity of noise, we used a noise level meter and thus rate and intensity was controlled in this way (22).

\subsection{Honey and Vitamin E Treatment}

The experimental group 2 received honey $(0.2 \mathrm{~mL}$ of $5 \%$ honey dissolved in water) and the experimental group 3 was given vitamin $\mathrm{E}$ ( $75 \mathrm{mg} / \mathrm{kg} /$ day) without delay during noise pollution by gavage and, using a custom-made instrument containing a tube with an approximate diameter $2 \mathrm{~mm}$, once a day at 18:00 hour for 50 days.

\subsection{Sex Hormones Levels Analysis}

After 50 days, blood sample was drawn from each rat's tail and sent to the laboratory for serum folliclestimulating hormone (FSH), luteinizing hormone (LH) and testosterone measurement. These measurements were done with the ELISA technique (CUSABIO kit, Japan).

\subsection{Morphometric Analysis of Male Fertilization}

Each experimental and control male rat was coupled with two females for one week. Then, vaginal plugpositive females were considered pregnant on day 0 . Finally prior to delivery, the pregnant female rats were killed on day 19 with anesthetic drugs and then the weight and rate of alive, dead and absorbed fetuses were measured.

\subsection{Statistical Analysis}

The experiments were replicated at least three independent times and data were presented as mean \pm SD and analyzed by one-way ANOVA followed by Tukey's post-hoc multiple group comparison test. The difference between groups was considered as statistically significant if $\mathrm{P}<0.05$. 


\section{Results}

\subsection{Sex Hormone Serum Levels}

To investigate noise pollution effect on sexual hormones levels, male rats were induced by noise pollution for 50 days and the results showed that the serum FSH and LH levels increased up to $8.06 \pm 0.9$ and $7.46 \pm$ $0.8 \mathrm{ng} / \mathrm{mL}$ while the concentrations of these hormones in the control group were $2.69 \pm 0.9$ and $2.35 \pm 0.3 \mathrm{ng} /$ $\mathrm{mL}$, respectively, with differences being significant $(\mathrm{P}<$ 0.05) (Figure $1 \mathrm{~A}, \mathrm{~B}$ ). Moreover, measurement of testosterone level in the control group was $8.61 \pm 0.33 \mathrm{ng} / \mathrm{mL}$ but noise stress could significantly decrease it to 3.25 $\pm 0.28 \mathrm{ng} / \mathrm{mL}$. Administration of vitamin E and honey significantly diminished these hormones levels to 2.97 \pm 0.6 and $4.33 \pm 0.4 \mathrm{ng} / \mathrm{mL}$ for FSH, and $3.39 \pm 0.36$ and $4.6 \pm 0.35 \mathrm{ng} / \mathrm{mL}$, for $\mathrm{LH}$, respectively $(\mathrm{P}<0.05)$ (Figure $1 \mathrm{~A}, \mathrm{~B})$. In contrast to serum gonadotropin hormones, plasma testosterone secretion significantly increased to $7.56 \pm 0.55$ and $5.4 \pm 0.75 \mathrm{ng} / \mathrm{mL}$ upon receiving vitamin $\mathrm{E}$ and honey by noise-exposed rats, respectively ( $\mathrm{P}$ $<0.05$ ) (Figure 1C).

\subsection{Morphometric Analysis of the Male's Fertil- ization Outcome}

As shown in Table 1, noise-exposed male rats were found to generate six live and one dead fetuses weighing $3.35 \pm 0.33 \mathrm{~g}$ upon mating with female rats compared to the control group that delivered nine live fetuses weighing $4.51 \pm 0.48 \mathrm{~g}(\mathrm{P}<0.05)$. Furthermore, our results showed that noise-exposed male rats could produce 11 and 9 live fetuses weighting $5.29 \pm 0.88 \mathrm{~g}$ and $5.29 \pm 0.31 \mathrm{~g}$ upon receiving honey and vitamin $E$, respectively, and these differences were significant compared to the untreated noise-exposed male rats $(\mathrm{P}$ $<0.05, \mathrm{P}<0.05)$
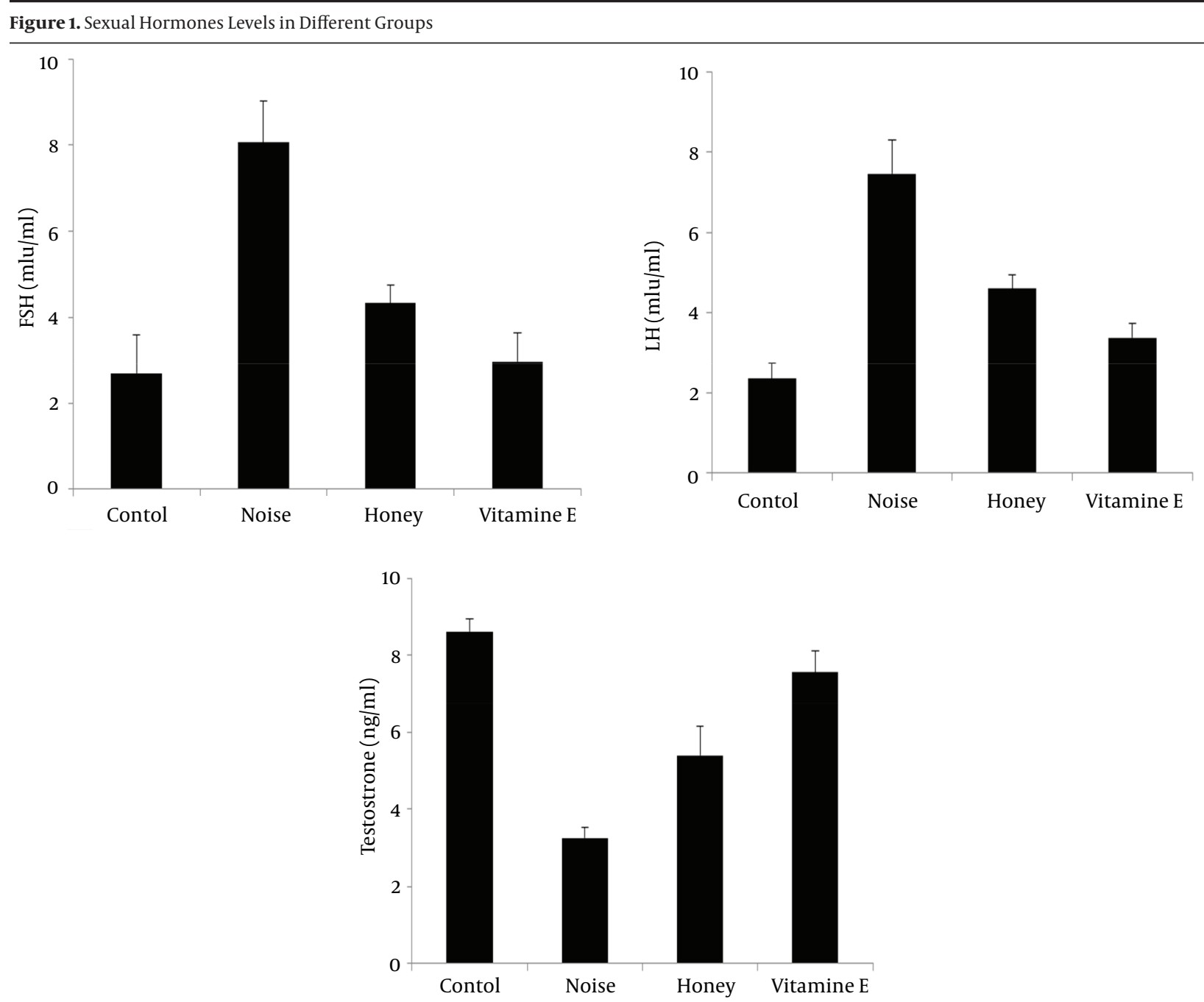

(A, B) Follicle stimulating hormone and LH levels increased in noise-exposed rats yet honey and vitamin E, significantly decreased the levels of these sexual hormones $(\mathrm{P}<0.05)$. (C) Noise also significantly diminished testosterone levels in rats compared to the control and the groups consumed honey and vitamin $\mathrm{E}(\mathrm{P}<0.05)$. 
Table 1. Number of Live and Dead Fetuses and Their Weights in Different Groups a

\begin{tabular}{lcccc}
\hline Groups & $\begin{array}{r}\text { Total } \\
\text { Fetus }\end{array}$ & $\begin{array}{c}\text { Living } \\
\text { Fetus, \% }\end{array}$ & Dead Fetus, \% & Fetus Weight \\
\hline Control & 9 & $9(100)$ & - & $4.51 \pm 0.48$ \\
Noise & 7 & $5(70)$ & $2(30)$ & $3.35 \pm 0.33^{b}$ \\
Honey & 11 & $11(100)$ & - & $5.29 \pm 0.88$ \\
Vitamin E & 10 & $9(90)$ & $1(10)$ & $5.29 \pm 0.31$ \\
\hline
\end{tabular}

$\mathrm{a}$ The rats treated with water were considered as the control group and the animals stressed with noise were divided to noise, honey or vitamin E groups. Data are presented as numbers and percentages for fetuses and mean \pm SD for weight of live fetuses.

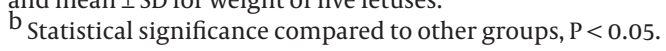

\section{Discussion}

Normally, the hormones FSH and LH, secreted from the hypophysis gland, control the primary functions of the testes that subsequently lead to adjustment of testosterone hormone production by leydig cells. However, some stress factors, i.e. noise pollution, may influence this balance (2). In the present study in the male rats exposed to noise stress the levels of plasma FSH and LH rose and the serum testosterone secretion fell sharply compared to the unexposed noise group. In accordance with the current results, Chandralekha et al. (6) also found that the serum FSH and LH levels raised by multi-folds in male rats exposed to a noise stress $(100 \mathrm{~dB})$ that in turn resulted in decreased plasma testosterone levels. Additionally, intermittent scrotal hyperthermia stress resulted in a rise of plasma FSH and LH and decrease of serum testosterone (22). Therefore, noise pollution may disrupt the concentration of steroid hormones and the neuroendocrine gonadal axis that in turn results in an increase in the rate of cellular damage to testicular tissue that causes a decrease in serum testosterone. Also it seems that every factor that can trigger the reduction or even inhibit gonadotropin and sex hormones secretion, normally can lead to induction of deleterious effects on germinative and somatic cells of testes parenchyma (23). Indeed, reduction in plasma testosterone levels may be due to disorganization of leydig cells, as stated in the previous study (11).

Some of these complications could probably be diminished by using natural curative agents that may protect the reproductive system within the stress period. The current study also pointed out that honey and vitamin E improved serum testosterone concentration, while declined plasma FSH and LH secretion in noise-exposed rats. Some studies have also confirmed these findings; Abdul-Ghani et al. reported that honey augments the spermatogenesis process without any disturbance in steroids hormones secretion i.e. gonadotropins and estradiol (10). Mahanem et al. (24) and Durriyyah, declared that if a suitable amount of honey was given to male rats, the spermatogenic cells lineage and also rates of sperm production would increase (25). Naseem et al. claimed that vitamin E enhanced sperm parameters (26).

Indeed, considering the above mentioned studies, from these findings it could be suggested that vitamin $\mathrm{E}$ and also more efficiently honey, due to their rich enzymatic and non-enzymatic antioxidants, neutralize injury patterns of testes integrity (i.e. due to the destructive effects of noise stress) and regulate anti-apoptotic patterns. Therefore, in general, each factor that affects the function of interstitial space cells (leydig and myoid cells) and epithelium germinal cells (sertoli and germ cells), may consequently lead to harmful effects on the neuroendocrine gonadal axis and in turn on the spermatogenic cell lineage. Therefore considering the above information, we can suppose that honey and vitamin E by having an impression on both neuroendocrine gonadal axis and testicular cells may modify deleterious processes (i.e. apoptosis or necrosis). The second assumption is that honey and vitamin E, by enhancing steroid hormones levels for sertoli cells, can have positive effects on nutrition of germ cells.

Therefore considering the above results and the results of this study it can be suggested that honey and vitamin $\mathrm{E}$ can be useful for keeping cells that are exposed to deleterious factors such as noise pollution alive. However, Asiyah et al. reported that honey has no positive influence on the sex hormones concentration in men (25). Therefore, further studies are needed to elucidate whether honey and vitamin E have a direct effect on sexual hormones production, or if decreased levels of FSH and LH are a compensatory mechanism that elevate testosterone levels. In the present study, to determine the fertility rate of noise-exposed rats treated with honey and vitamin E, male rats were coupled with females. Surprisingly, it was observed that the continuing effects of noise stress injury could reduce the survival rate and weight of fetuses and the number of live fetuses.

Previously, it has been shown that honey and vitamin $\mathrm{E}$ facilitate the recovery of spermatogenesis process by increasing the motility and production of spermatozoa in the epididymis that finally results in enhanced fertilization rate in rats $(11,18,25)$. It was also confirmed that the level of sorbitol dehydrogenase (SDH), as a key enzyme in spermatogenesis, increased following honey consumption (10). Honey also has protective effects on sertoli cells and nourishes them to enhance mature spermatozoa count and affect overall sperm quality. Mahanem et al. indicated that in male rats exposed to cigarette smoking, serum LH, FSH and testosterone levels changed to optimum levels upon receiving honey (24). Zakem and Alliston (27) reported that in pregnant rats exposed to 83 to $95 \mathrm{~dB}$ of noise, the mortality of fetus and newborn low birth weight and size were higher than pregnant rats not exposed to noise.

In another study, Kimmel et al. (28) observed that in the pregnant rats exposed to $100 \mathrm{~dB}$ of noise the number of alive fetuses and survival rate of fetuses were decreased because of increased fetal resorption rate. It seems that 
noise pollution has harmful effects on the fertility of males. Also these findings may support a natural curative approach rather than pharmaceutical synthetic drugs to optimize both neuroendocrine gonadal axis and testicular integrity induced by pathogenesis stress (i.e. noise) and enhance fertility rate in men.

\section{Acknowledgements}

The present study was extracted from the master's thesis of Mr. Asghar Rajabzadeh.

\section{Funding/Support}

This study was supported by a research grant from the Ahvaz Jundishapur University of Medical Sciences, Ahvaz, IR Iran.

\section{References}

1. von Borell E, Dobson H, Prunier A. Stress, behaviour and reproductive performance in female cattle and pigs. Horm Behav. 2007;52(1):130-8.

2. Swami CG, Ramanathan J, Charan Jeganath C. Noise exposure effect on testicular histology, morphology and on male steroidogenic hormone. Malays J Med Sci. 2007;14(2):28-35.

3. Cosa M, Cosa G. [Annoyance, disturbance and damage caused by noise and vibrations]. Ann Ig. 1989;1(1-2):133-56.

4. Faldikova L, Diblikova I. Effects of nutrition, social factors and chronic stress on the mouse Leydig cell testosterone production. 2001;6:160-8.

5. Almeida SA, Kempinas WG, Lamano Carvalho TL. Sexual behavior and fertility of male rats submitted to prolonged immobilization-induced stress. Braz J Med Biol Res. 2000;33(9):1105-9.

6. Chandralekha G. . The effect of noise induced stress on the male reproductive endocrine glands of Albino rats. [Phd.].: Dr. MGR Medical University and Research Chennai; 2002.

7. Nawrot PS, Cook RO, Hamm CW. Embryotoxicity of broadband high-frequency noise in the CD-1 mouse. J Toxicol Environ Health. 1981;8(1-2):151-7.

8. Bauche F, Fouchard MH, Jégou B. Antioxidant system in rat testicular cells. FEBS. 1994;349(3):392-6.

9. Gu W, Hecht NB. Developmental expression of glutathione peroxidase, catalase, and manganese superoxide dismutase mRNAs during spermatogenesis in the mouse. J Androl. 1996;17(3):25662.

10. Abdul-Ghani AS, Dabdoub N, Muhammad R, Abdul-Ghani R, Qazzaz M. Effect of Palestinian honey on spermatogenesis in rats. $J$ Med Food. 2008;11(4):799-802.

11. Mohamed M, Sulaiman SA, Jaafar H, Sirajudeen KN. Antioxidant protective effect of honey in cigarette smoke-induced testicular damage in rats. Int J Mol Sci. 2011;12(9):5508-21.

12. Estevinho L, Pereira AP, Moreira L, Dias LG, Pereira E. Antioxidant and antimicrobial effects of phenolic compounds extracts of Northeast Portugal honey. Food Chem Toxicol. 2008;46(12):3774-9.

13. Gheldof N, Wang XH, Engeseth NJ. Identification and quantification of antioxidant components of honeys from various floral sources. J Agric Food Chem. 2002;50(21):5870-7.

14. Mato I, Huidobro JF, Simal-Lozano J, Sancho MT. Significance of nonaromatic organic acids in honey.JFood Prot. 2003;66(12):23716.

15. Kessopoulou E, Powers HJ, Sharma KK, Pearson MJ, Russell JM, Cooke ID, et al. A double-blind randomized placebo cross-over controlled trial using the antioxidant vitamin E to treat reactive oxygen species associated male infertility. Fertil Steril. 1995;64(4):825-31.

16. Shalaby MA, Elzorba HY. Protective effect of celery oil, vitamin e and their combination against testicular toxicity in male rats. GV. 2010;5(2):122-8.

17. Kutlubay R, Oguz EO, Can B, Guven MC, Sinik Z, Tuncay OL. Vitamin E protection from testicular damage caused by intraperitoneal aluminium. Int JToxicol. 2007;26(4):297-306.

18. Momeni HR, Oryan S, Eskandari N. Effect of vitamin E on sperm number and testis histopathology of sodium arsenite-treated rats. Reprod Biol. 2012;12(2):171-81.

19. Sahinturk V, Guclu C, Baycu C. Protective effects of vitamin E on ethane dimethane sulfonate-induced testicular toxicity in rats. Asian JAndrol. 2007;9(1):117-24.

20. Erat M, Ciftci M, Gumustekin K, Gul M. Effects of nicotine and vitamin $\mathrm{E}$ on glutathione reductase activity in some rat tissues in vivo and in vitro. Eur J Pharmacol. 2007;554(2-3):92-7.

21. Noguchi J, Yoshida M, Ikadai H, Imamichi T, Watanabe G, Taya K. Age-related changes in blood concentrations of FSH, LH and testosterone and testicular morphology in a new rat sterile mutant with hereditary aspermia. J Reprod Fertil. 1993;97(2):433-9.

22. Heidary F, Ahmadi R, Lotfi A. The effects of cigarette or hookah smoking on serum levels of $\mathrm{lh}, \mathrm{fsh}_{\text {sh }}$ or testosterone in male rats.; 2012.

23. Moustafa MH, Sharma RK, Thornton J, Mascha E, Abdel-Hafez MA, Thomas AJ, et al. Relationship between ROS production, apoptosis and DNA denaturation in spermatozoa from patients examined for infertility. Hum Reprod. 2004;19(1):129-38.

24. Mahanem M, Siti Amrah S, Yatiban MK, Hasnan J. Effect of 'tualang honey'on spermatogenesis in rats. Malay J Med Sci. 2007;14(1):126.

25. Durriyyah S. Effects of nicotine and Gelam honey on testis parameters and sperm qualities of juvenile rats. Scientific Research and Essays. 2011;6(26):5471-4.

26. Naseem M, Goh YM, Hafandi A, Amal NM, Kufli CN, Rajion MA. Effects of vitamin E and soybean oil supplementation on sperm parameters in male Sprague-Dawley rats. Trop Biomed. 2007;24(2):45-8.

27. Zakem HB, Alliston CW. The effects of noise level and elevated ambient temperatures upon selected reproductive traits in female Swiss-Webster mice. Lab Anim Sci. 1974;24(3):469-75.

28. Kimmel CA, Cook RO, Staples RE. Teratogenic potential of noise in mice and rats. Toxicol Appl Pharmacol. 1976;36(2):239-45. 